\title{
La autonomía en dilemas. El federalismo y los Territorios Nacionales en el derecho constitucional argentino (1870-1920)
}

\author{
Q Lisandro Gallucci \\ Universidad Nacional de San Martín - Consejo Nacional de Investigaciones Científicas y Técnicas, \\ Argentina. \\ lisandrogallucci@gmail.com
}

Artículo recibido: 11 de febrero de 2019. Aprobación final: 11 de junio de 2019.

\section{Resumen}

Mediante un recorrido por las obras de un conjunto de figuras relevantes del derecho constitucional en Argentina entre 1870 y 1920, este artículo ofrece un estudio sobre las formas en que aquellas concibieron el lugar de los Territorios Nacionales en el régimen federal consagrado en la Constitución de 1853. Sus reflexiones sobre la transformación de esas unidades dependientes del gobierno federal en nuevas provincias, ofrecen algunos indicios acerca de las dificultades que rodearon a ese cambio de estatus. El examen de esas ideas permite además descubrir importantes aspectos sin embargo poco atendidos por la historiografía relativa al federalismo argentino de dicho periodo, tales como la condición jurídico-política de las provincias y los fundamentos de su autonomía. La resolución que tuvieron los debates desarrollados en torno a dichas cuestiones, sugiere la existencia de un régimen federal más resistente ante tendencias centralistas de lo que por lo general se supone.

Palabras clave: Argentina, Federalismo, Autonomía, Derecho Constitucional, Territorios Nacionales.

Autonomy in Dilemmas. Federalism and the National Territories in the Argentine Constitutional Law (1870-1920)

\footnotetext{
Abstract

The article offers an analysis of the ways in which a group of relevant experts of Argentine constitutional law between 1870 and 1920 conceived the place of the National Territories in the federal regime enshrined in the Constitution of 1853.
} 
The difficulties derived from the transformation of the provincial autonomies and their new relationship with the nation state are analyzed. It is also intended to shed light on important aspects scarcely attended by the historiography related to the Argentine federalism of that period, such as the legal-political condition of the provinces and the foundations of their autonomy. The results of these debates suggest the existence of a federal regime that is more resistant to centralist tendencies than is generally supposed.

Key Words: Argentina, Federalism, Autonomy, Constitutional Law, National Territories.

A Juan Carlos Gallucci

Hacia mediados de la década de 1880, la República Argentina había logrado extender su dominio soberano sobre una superficie notoriamente mayor a la que mostraba apenas dos décadas atrás, cuando la provincia de Buenos Aires se incorporó de forma definitiva al conjunto de las otras trece que integraban la Confederación. Como es bien conocido, la conquista de los vastos espacios que se extendían más allá de las provincias, tanto al norte como al sur del país, implicó el sometimiento de los grupos indígenas que, con distinta antigüedad, se encontraban en esas tierras. No escapa tampoco al conocimiento general que, lejos de constituir un fenómeno exclusivo del caso argentino, similares políticas de expansión territorial fueron seguidas en forma contemporánea por otros estados, no sólo en espacios ultramarinos sino también en el ámbito sudamericano. Si bien, como resultado de esa competencia internacional, la definición de los límites con los países vecinos se extendería por varias décadas, dando lugar a diferendos en los que se recurrió a arbitrajes internacionales, nada de ello impide reconocer que fue en la década de 1880 cuando la Argentina adquirió una extensión muy similar a su actual superficie. Esta dramática expansión, decisiva en la formación de la Argentina moderna, implicó la duplicación de su territorio soberano, imprimió un giro definitivo en lo relativo a las fronteras con los indígenas y, tanto por esto último como por la incorporación de cientos de miles de kilómetros cuadrados, abrió nuevas posibilidades para el crecimiento económico del país.

Pero ese espectacular aumento del territorio soberano argentino también colocó al joven Estado nacional ante el desafío de gobernar aquellas vastas y mayormente despobladas extensiones, y de definir además el lugar que habrían de ocupar dentro del régimen representativo federal consagrado en la Constitución. Luego de algunas experiencias provisorias, como la creación de las gobernaciones de Chaco (1872) y de la Patagonia (1878), sobre cuyas geografías sin embargo no se ejercería control efectivo, las autoridades argentinas recién dieron una respuesta a la cuestión del estatus de las nuevas tierras mediante la sanción, en 1884, de una ley general de Territorios Nacionales que llevó el número 1.532. ${ }^{1}$ Con esta normativa

1 A esos antecedentes cabe agregar el de la creación del Territorio de Misiones, en 1881, en el marco de disputas limítrofes con el Imperio del Brasil - resueltas en 1885 mediante el laudo de Estados Unidossobre tierras que a su vez la provincia de Corrientes reclamaba como propias, aunque no ejercía un gobierno efectivo sobre toda la extensión de las mismas. Podría atribuirse la federalización de Misiones a una represalia del gobierno nacional contra Corrientes por el apoyo que sus autoridades dieron a la revolución de 1880, que llevó a que la provincia fuera intervenida ese mismo año. Es de todas formas 
no sólo se definió la forma de gobierno que habría de regir en ellos, en lo inmediato encabezada por un gobernador designado por el Ejecutivo nacional con el acuerdo del Congreso, sino que al mismo tiempo se determinó que los Territorios -que en conjunto representaban casi la mitad de la entera extensión territorial argentinadebían ulteriormente dar lugar a nuevas provincias que habrían de sumarse, en plena igualdad, a las ya existentes. El criterio que se fijó entonces fue estrictamente demográfico: en el orden local, toda localidad que contase con más de mil habitantes domiciliados podía obtener la constitución de un concejo municipal y de una justicia de paz electivos; a nivel del Territorio, todo aquel que tuviese más de treinta mil habitantes accedería a la posibilidad de formar una legislatura propia, mientras que al superar la cantidad de sesenta mil quedaría habilitado para ser elevado a la condición de provincia. Esta sucesión de etapas a través de la cual se pretendía conducir a los Territorios por niveles crecientes de autonomía que culminarían en la obtención del estatus de provincia, se reveló como una fórmula de aplicación mucho menos sencilla de lo inicialmente imaginado por los legisladores de 1884 . Lejos de ajustarse a esa regla demográfica, la transformación de los Territorios en nuevas provincias se produjo, en la mayoría de los casos, cuando ya habían superado largamente la cantidad de población que la ley fijaba a tal efecto.

El propósito de este artículo consiste en explorar las razones de la ineficacia de aquel principio demográfico, que había sido adoptado para asegurar que el proceso de conversión de los Territorios en provincias estuviera sujeto a una regla fija. Con el ánimo de contribuir en tal sentido, este estudio está dedicado a analizar una de las dimensiones más relevantes del problema, como es la del tratamiento que en el ámbito del derecho constitucional se hizo de la cuestión de la elevación de los Territorios al estatus de provincias. ${ }^{2}$ La reconstrucción de los argumentos expuestos por quienes se pronunciaron sobre el asunto permite echar luz sobre los modos, no unívocos y menos aún invariables, en que desde aquel ámbito se reflexionó acerca de la inédita circunstancia que para la experiencia constitucional argentina significaba la creación de nuevas provincias a partir de unidades administrativas creadas sobre tierras de reciente incorporación al dominio soberano de la nación. Examinar las distintas miradas que desde el derecho constitucional se ofrecieron en torno a dicha transformación no sólo es necesario para comprender mejor las dificultades que la envolvieron. Además, al situar el

necesario considerar, más allá de una específica coyuntura, el problema de más larga data $-\mathrm{y}$ del que Corrientes no era el único caso- de la indefinición de los límites internacionales e interprovinciales, especialmente agudo allí donde ambos aspectos se presentaban de forma simultánea. Cabe notar, en este sentido, que la federalización de Misiones se produjo en forma subsidiaria a la fijación de los límites de la provincia de Corrientes, que finalmente comprendieron un espacio mayor al originalmente propuesto en el proyecto que al efecto elaboró el Poder Ejecutivo Nacional.

2 Algunas publicaciones previas han abordado las miradas que distintos profesionales de las leyes plantearon con relación a los Territorios (Ruffini, 2007a). En tales estudios las consideraciones hechas por las más importantes figuras del derecho constitucional son equiparadas a las de abogados que sólo se expresaron sobre el particular en breves tesis por lo general obligatorias. Sin considerar jurista a todo graduado en derecho, este estudio se ocupa en forma exclusiva de figuras relevantes del derecho constitucional argentino, bajo la premisa de que en su condición de autoridades en dicho ámbito sentaron una serie de argumentos - no siempre convergentes - sobre la condición jurídica de los Territorios que ofrecen indicios para entender el tratamiento legislativo que se dio a los mismos. Cabe señalar que la circulación de las reflexiones de esos juristas entre quienes fueron sus estudiantes en la universidad, quienes en no pocos casos devinieron legisladores, ya ha sido objeto de tratamiento específico (Gallucci, 2018). Sobre la enseñanza universitaria del derecho en Argentina, Tanzi (2011) y Buchbinder (2012). 
problema en el contexto más amplio de los suscitados en torno al federalismo argentino entre las décadas finales del siglo XIX y las primeras del siguiente, resulta posible descubrir aspectos desatendidos por la historiografía sobre la temática relativa a esa época. Aun cuando en los últimos años una creciente producción se ha ocupado de abordar distintas dimensiones del régimen federal de aquel periodo, sometiendo a revisión cierta imagen tradicional del mismo como dominado por un proceso de continua centralización política y administrativa que mostraba a las provincias como víctimas netas de un ascendente Estado nacional, no deja de ser cierto que la perspectiva de esos renovados estudios ha permanecido restringida a las relaciones entre las provincias y el Estado federal, como si las tensiones presentes en el federalismo argentino se hubiesen reducido a la distribución de poder y de recursos entre tales entidades. ${ }^{3}$ Los desafíos derivados del espectacular crecimiento territorial que el país experimentó alrededor de 1880, que implicó la incorporación de un área tan vasta como la representada por el conjunto de las provincias entonces existentes, resultan así ignorados como pertenecientes a un orden de cosas ajeno al federalismo y del que por lo tanto no sería necesario ocuparse. En el mejor de los casos, los Territorios Nacionales son reducidos a manifestación de inspiraciones unitarias mal contenidas por un molde federal (Botana, 1993: 241; 2015: 257). La propia historiografía dedicada a los Territorios no ha contemplado a tales espacios más que como testimonio de una vocación centralista a la que ha señalado, también, como causa del incumplimiento de la normativa en cuanto a la conversión de aquellos espacios en nuevas provincias (Arias Bucciarelli, 2013; Ruffini, 2007b).

Como se busca demostrar en estas páginas, las consideraciones que desde el derecho constitucional se hicieron en torno a los desafíos que la invención de los Territorios introdujo en el régimen federal, no se limitaron a definir el estatus jurídico de dichos espacios, ni a responder a la cuestión de su reconocimiento como provincias. Aun si estos constituían obligados puntos de referencia en toda intervención relativa a los Territorios, es necesario advertir que, al abordar dichos problemas, las figuras académicas aquí contempladas se ocupaban de una pieza fundamental de todo el federalismo argentino, como era el concepto mismo de provincia. En efecto, reflexionar en torno a la posibilidad de otorgar a un Territorio el estatus provincial implicaba partir de una cierta noción acerca de esta última calidad y, de manera subsidiaria, definir cómo podía ser obtenida por unidades desprovistas de ella. Es importante subrayar que quienes expresaron sus posiciones en torno a la cuestión de los Territorios no siempre ofrecieron una definición precisa y explícita del concepto de provincia, lo que significa que el mismo deba a veces ser reconstruido a través de las observaciones que efectuaron sobre otros aspectos del federalismo argentino. De esta manera, seguir las variaciones de las que fue objeto la cuestión de los Territorios entre 1870 y 1920 -para cuando surgen nuevas corrientes de estudio histórico-constitucional, según han señalado Chiaramonte y Buchbinder (1992: 116)- puede ofrecer indicios significativos sobre

3 Sin espacio para un repaso exhaustivo de esa nueva historiografía sobre el federalismo argentino, una muestra de algunas de las líneas de investigación actuales puede encontrarse en las compilaciones de Bragoni y Míguez (2010) y de Alonso y Bragoni (2015). 
ciertas transformaciones decisivas, si bien poco atendidas, de un régimen federal que no dejó de experimentar cambios a lo largo de dicho periodo.

El recorrido propuesto en este estudio se inicia con una primera sección dedicada a señalar los factores que permiten identificar la formación de un derecho constitucional argentino a partir de la década de 1870, y a observar de qué forma esa evolución influyó sobre el modo de pensar el estatus de los Territorios. Siempre con el eje puesto en el tratamiento que se hizo de la condición jurídica de estos últimos, en el segundo apartado se analizan los debates en torno al régimen federal suscitados por el progresivo aumento de las capacidades del Estado nacional que tuvo lugar desde la década de 1880. En la tercera parte, se abordan los efectos que hacia el cambio de siglo nuevas aproximaciones, de pretensión científica, tuvieron tanto en las evaluaciones sobre el estado general del federalismo argentino como en las respuestas planteadas a tales diagnósticos. Por último, las conclusiones apuntan a señalar la conveniencia de ampliar los enfoques sobre el federalismo argentino para contemplar también a los Territorios como parte de esa historia y superar así cierta persistente tendencia a restringirla al escenario de las catorce provincias iniciales.

\section{Hacia un federalismo argentino}

El concepto de federalismo formó desde temprano parte de los lenguajes políticos que se desplegaron al calor de la disolución del virreinato del Río de la Plata y de los posteriores esfuerzos de los actores políticos por fundar una comunidad política independiente de la Corona española (Chiaramonte, 1997). Los conflictos entonces suscitados en torno a la fórmula institucional que debía dar sostén a ese nuevo orden, pronto enfrentaron a quienes auspiciaban el mantenimiento, en molde republicano, de un modo centralizado de gobierno, con aquellos otros que, en parte inspirados en la experiencia de los Estados Unidos, propugnaban la adopción de un régimen que diera a las provincias -ellas mismas surgidas de las disputas en torno a la definición de la entidad soberana- la facultad de darse un gobierno propio. Así, los distintos ensayos institucionales que se sucedieron durante la primera mitad del siglo XIX alimentaron profundas disputas acerca de la naturaleza y el alcance de la nueva soberanía que se buscaba establecer. Tales controversias no tuvieron una índole puramente intelectual, al menos en el sentido de que las querellas abiertas en torno a los inéditos desafíos que los actores enfrentaban, no fueron ajenas a los también inéditos niveles de violencia que marcaron la vida política de esas décadas (Halperin Donghi, 2015 [1972]). La fragmentación del escenario rioplatense que se desplegó a partir de 1820, dio lugar al surgimiento de entidades de un nuevo tipo, las provincias, que adquirieron dimensión política gracias a la supresión de instituciones características del extinto orden colonial, a la inclusión del ámbito rural en la representación política y también, aunque no en todos los casos, mediante la sanción de sus propias constituciones (Ternavasio, 2000, 2002; Agüero, 2017). Sin embargo, las décadas posteriores transcurrieron sin que se lograse dar forma constitucional a 
una unidad política que, pese al celo con el que las provincias abrazaban su recién proclamada soberanía, no desapareció por completo del plano de las expectativas de los actores del periodo.

Nada de esto implica postular, como lo hacía una perspectiva ampliamente revisada por la historiografía más reciente, que había una unidad política en ciernes a la que una serie de obstáculos impedía su manifestación plena. Las investigaciones desarrolladas desde hace ya algunas décadas han permitido comprender la formación de esa unidad política como uno de los resultados posibles de las diversas problemáticas abiertas durante la primera mitad del siglo XIX, entre las cuales el federalismo ocupó un lugar relevante. De esta manera, ha sido posible dar cuenta de los cambios semánticos que durante ese periodo se operaron en torno al término mismo de federalismo, advirtiendo inclusive la existencia de concepciones confederalistas que no allanaban la formación de dicha unidad política (Chiaramonte, 1993: 85; Goldman, 1998: 111). Asimismo, la naturaleza jurídico-política de las provincias, caracterizadas sea como "estados soberanos" (Chiaramonte, 1993: 113) sea como "repúblicas provinciales" (Ternavasio, 2009: 130), ha sido expuesta como producto de meditadas construcciones institucionales antes que como un fruto espontáneo de la sociedad local que las destinaba a unirse bajo un régimen federal.

Pero aun cuando el federalismo estuvo presente en el lenguaje político de la primera mitad del siglo, ya como modelo de gobierno ya como vector de identidades políticas (Goldman y Salvatore, 2005; Myers, 1995), y sin dejar de entender que lejos estaba de marcar el horizonte hacia el que habrían estado fatalmente dirigidas las provincias, debe admitirse que fue sólo a partir de la sanción de la Constitución de 1853 que cobró forma institucional. La adopción de un régimen federal para la república a la que mantuvieron el nombre de Confederación, fue concebida por los constituyentes como la fórmula capaz de lograr la fundación de una soberanía superior a la de las provincias y, al mismo tiempo, preservar la personalidad política de estas últimas. La apuesta significaba un hecho novedoso en la historia institucional del país y las dificultades de su puesta en marcha no tardaron en surgir, como lo hizo patente, entre otros aspectos, la secesión de la provincia de Buenos Aires durante toda una década (Sabato, 2012: 67 y ss). Pero si al adoptar una forma federal de gobierno los constituyentes se adentraron por una vía que hasta entonces no habían transitado, lo cierto es que apelaron a los antecedentes que les ofrecían experiencias de otras latitudes, como de forma paradigmática fue el caso de los Estados Unidos.

El régimen representativo y federal establecido en el país del norte contaba entonces con más de medio siglo de vigencia. Desde el agitado escenario rioplatense, la eficacia de ese "federalismo unitario", como lo calificaba Juan Bautista Alberdi (1852: 135), era reconocida tanto en la estabilidad política que había proporcionado a los Estados Unidos, como en el formidable crecimiento demográfico y económico que esas condiciones le habían permitido alcanzar. Sería de cualquier modo equivocado suponer que la adopción de un régimen federal en Argentina fue producto de un mero trasplante, o sostener que, debido a las 
modalidades que allí adquirió, el federalismo "nunca se hizo realidad" (Miller, 1997: 1487). ${ }^{4}$ Con entusiasmo o con resignación, distintos observadores advertían que el federalismo había terminado por convertirse en un rasgo inevitable que todo diseño constitucional que aspirase a perdurar debía admitir. Las divergencias surgían al pensar de qué modo tenía que producirse tal adaptación. De cualquier manera, el reconocimiento de las raíces que el federalismo podía tener en el país, no opacaba la contemplación de los Estados Unidos como el laboratorio donde se había logrado una virtuosa combinación entre el poder federal y los derechos de los estados. La apreciación del federalismo como mecanismo de limitación del poder, que a propósito de los Estados Unidos ya había sido señalada por Tocqueville (2010 [1835-1840]), resultaba así atractiva para quienes entendían que las posibilidades de progreso del país radicaban más en la amplitud de las libertades individuales que en la fuerza del gobierno.

La imagen de los Estados Unidos como vanguardia del camino que la Argentina debía transitar se vio reforzada en las décadas de 1860 y 1870. Si la reincorporación de Buenos Aires pareció prometer la estabilización del régimen federal, los levantamientos contra el gobierno nacional que tuvieron lugar en distintos puntos del interior pronto demostraron lo contrario (De la Fuente, 2007). Los desafíos políticos pero también jurídicos impuestos por el nuevo escenario animaron debates acerca de cuestiones decisivas del régimen federal tales como la intervención a las provincias, la declaración del estado de sitio, la administración de justicia y la propiedad de los recursos aduaneros, entre otros aspectos (Zimmermann, 2015; Cucchi y Romero, 2017). Ante estos problemas, la experiencia de los Estados Unidos fue considerada como una fuente de especial relevancia para evaluar posibles respuestas. De esta manera, las reflexiones jurídicas y las resoluciones institucionales que sobre tales cuestiones habían sido adoptadas por aquella nación, despertaron el interés de los hombres de la política y del derecho, que impulsaron la traducción y difusión de las obras que reconocidos juristas norteamericanos dedicaron al constitucionalismo y al federalismo (Zimmermann, 2014). La recepción de esa literatura estuvo lejos de ceñirse a una única lectura, y las que se efectuaron no fueron ajenas a las motivaciones que cada intérprete tenía en subrayar determinados aspectos y soslayar otros menos convenientes a la posición que predicaba. Pero aun en esa diversidad de apreciaciones, los Estados Unidos constituían la referencia común en la que buscaban respaldo quienes intervenían, ya fuera en sus propias obras, a través de la prensa, en las cátedras universitarias o inclusive en el parlamento, en los debates librados sobre cuestiones de materia constitucional y federal.

Con todo, ese panorama comenzó a cambiar hacia mediados de la década de 1870. La idea de que el examen de la historia constitucional de los Estados Unidos permitiría extraer lecciones más generales acerca del funcionamiento del federalismo, y por lo tanto en todo pertinentes para el caso argentino, empezó a ser impugnada por quienes entendían que las experiencias federales de ambos países no eran asimilables. Una figura decisiva en este cambio de perspectiva fue la de José 
Manuel Estrada, quien en 1869 fue designado al frente de la cátedra de Historia e Instrucción Cívica del Colegio Nacional de Buenos Aires y en 1875, sin haberse graduado en leyes, fue puesto a cargo de la cátedra de Derecho Constitucional de la Universidad de Buenos Aires, que había dejado vacante quien desde 1868 había sido su primer titular, el colombiano Florentino González. Si para este último los Estados Unidos ofrecían el mejor modelo posible para la Argentina por estar su Constitución "calcada" de la de aquéllos (González, 1871: 102), para Estrada era en cambio necesario partir del estudio de la "constitución no escrita" de la nación argentina, de la cual concluía que "nuestra federación, por su espíritu y consiguiente tendencia, rechaza las doctrinas eversivas de la escuela jeffersoniana" (Estrada, 1877: 305). El rechazo de Estrada hacia una adopción demasiado entusiasta de los antecedentes estadounidenses derivaba de la premisa, ya sostenida por Alberdi y también por Bartolomé Mitre, de que la nación argentina era preexistente a las provincias. Esto significaba pensar que la Constitución de 1853 no había sido un pacto de unión entre entidades soberanas, como había ocurrido en los Estados Unidos, sino el documento por el que la nación argentina se había dado a sí misma una forma federativa de gobierno. Así disímiles los caminos que una y otra nación habían recorrido hasta adoptar un régimen federal, la validez que las observaciones realizadas en torno a los Estados Unidos podían tener para la Argentina quedaba sensiblemente cuestionada. Había entonces que dar cuenta de un federalismo argentino no reductible a los caracteres formales de un modelo abstracto.

El reclamo que Estrada hacía de una perspectiva más atenta a la "complexión orgánica" (1877: 305) de la nación argentina no lo llevaba a rechazar por completo cualquier mirada al régimen federal estadounidense. Uno de los aspectos sobre los que juzgó apropiado examinarla en busca de respuestas a los desafíos enfrentados por el federalismo argentino fue el relativo a la forma de gobierno que se debía dar a las vastas extensiones que, situadas más allá de los límites provinciales, eran reclamadas como dominios de la nación, aun cuando todavía no se tenía control efectivo sobre ellas. "¿Cómo deben adaptarse a la índole del federalismo las leyes destinadas a organizar los Territorios?", se preguntaba Estrada (1885: 124). A su entender, el único modo de conciliar la existencia de unidades sujetas al gobierno nacional con el régimen federal radicaba en "preparar la conversión del territorio en provincias, como vemos que lo hace la legislación de los Estados Unidos" (Estrada, 1885: 125).

Pero de esa respuesta se desprendía otra pregunta, relativa a qué era lo que determinaba la calidad provincial. Aun si Estrada admitía que las provincias constituían "verdaderas corporaciones" (1895:376), no las imaginaba como fruto de un desarrollo orgánico de cada sociedad local. Sostenía en cambio con crudeza que "las provincias se han formado a consecuencia de desgarramientos de la nacionalidad” (Estrada, 1895: 470), en evidente referencia a la fragmentación política del espacio rioplatense que siguió a 1820. Las provincias argentinas no eran así en modo alguno equiparables a los estados norteamericanos, lo que reforzaba su cuestionamiento a quienes querían hacer de estos últimos un modelo aplicable en el país. Según explicaba Estrada, siguiendo una visión alberdiana sobre la 
cuestión, en el caso argentino "el legislador se vio forzado a aceptar en categoría de provincias todos los centros que tal derecho reclamaban, cediendo a los impulsos de facciones revolucionarias y a los arrebatamientos de la anarquía, aunque no tuvieran capacidad efectiva para gobernarse por sí mismas, y satisfacer sus propias necesidades, en una palabra, fue menester aceptar los productos de la revolución” (1895:317-318). Este accidental arribo de las provincias a la existencia institucional explicaba, según Estrada, las dificultades que tenían para desenvolverse de forma autónoma. Su temprano convencimiento de que no eran todavía "cuerpos políticos verdaderamente capaces de autonomía" (Estrada, 1885: 123), se veía reforzado al echar una mirada a la realidad de las provincias, de la que concluía que "son, en su mayoría tan insuficientes e incapaces de desempeñar su propio papel, que no pueden menos de producir una imperfección general del sistema federativo de gobierno" (Estrada, 1895: 317). Como se advierte, el punto crucial radicaba para Estrada en los fundamentos económicos que daban soporte a una autonomía de otro modo puramente formal. En sus propias palabras, "si una provincia necesita subsidios, no tiene capacidad financiera; $y$ en el terreno de la doctrina, es indudable que una agrupación tal de personas, no se puede llamar provincia” (Estrada, 1895: 469).

La premisa de que "la capacidad financiera es la condición esencial para ser provincia” (Estrada, 1895: 470) entrañaba un corolario muy sencillo para la futura conversión de los Territorios en nuevas provincias, que no era otro que el de alcanzar dicha capacidad: "el día que los territorios la obtienen, pueden presentarse ante el Congreso pidiendo se declare su soberanía” (Estrada, 1895: 470). Este énfasis en la capacidad económica como el verdadero sostén de la autonomía política no parece haber constituido una opinión aislada. De hecho, en el proyecto de ley de Territorios Nacionales que el Poder Ejecutivo envió al Congreso en 1883, se propuso, al definir los requisitos que aquellos debían satisfacer para ser reconocidos como provincias, que además de tener una población superior a sesenta mil habitantes, contasen con los recursos suficientes para cubrir su presupuesto de gastos. ${ }^{5}$ Aun si esta última condición no fue incluida en la ley finalmente sancionada -como ya fue señalado, el único requisito que se estableció fue el de dicho umbral demográfico- su misma formulación resulta un sugestivo indicio de que concepciones como la que Estrada tenía acerca de la calidad provincial no eran fruto de una aislada especulación intelectual sino, al contrario, compartidas por miembros de los más altos círculos gubernamentales de la década de 1880.

5 Esa cláusula había sido introducida por los autores del proyecto original, el entonces ministro del Interior, Bernardo de Irigoyen, y el secretario de la misma cartera, Federico Pinedo. Los legisladores que acompañaron la propuesta consideraban, en una línea de razonamiento similar a la formulada por Estrada, que el requisito de capacidad económica aseguraría que las futuras provincias fueran verdaderamente autónomas, como entendían no lo eran varias de las existentes. No sólo los legisladores de estas últimas provincias encontraban inadmisible la propuesta de sujetar la autonomía a la capacidad económica. En un sentido más general, la mayoría de los diputados rechazó la cláusula por juzgar inconveniente que la adquisición de un atributo permanente, el de la calidad de provincia, quedara sujeto a un elemento forzosamente variable como la recaudación fiscal o las necesidades presupuestarias de una gobernación. Sobre la cuestión, Gallucci (2016: 73-76). 


\section{Genealogías disputadas}

Fue durante esa misma década que una serie de cambios cruciales terminarían por dar al régimen federal una fisonomía muy diferente a la que hasta entonces había tenido. En 1880, las tensiones acumuladas entre el gobierno nacional y el de la provincia de Buenos Aires, se vieron profundizadas por la elección de Julio A. Roca como presidente de la nación tras derrotar al gobernador bonaerense, Carlos Tejedor, quien escasos meses más tarde llevó a la provincia a levantarse en armas contra las autoridades federales (Sabato, 2008). La derrota, también militar, a manos del todavía ministro Roca, se selló poco después con la sanción de la ley que dispuso la federalización de la ciudad de Buenos Aires, quitando a la provincia la que había sido su capital y más importante ciudad. El triunfo de las fuerzas nacionales dio también cauce a la prohibición, impuesta a las provincias, de organizar cuerpos militares de cualquier índole, aunque el recurso a las armas no desapareció en lo inmediato del repertorio de formas de contestación contra el gobierno federal (Sabato y Macías, 2013). Extinguida esa fuente de desafíos, las autoridades nacionales dieron impulso a una serie de medidas que tendían a concentrar en el Estado federal funciones hasta entonces ejercidas por las provincias o por la iglesia, como la instrucción pública, la emisión de moneda y el registro de los actos civiles, entre otras (Botana y Gallo, 1997).

Esta progresiva ampliación del poder del Estado federal fue desde temprano denunciada por figuras de la oposición como un proceso de sometimiento de las provincias a la voluntad centralizadora del gobierno nacional. Entre quienes insistieron con más vehemencia sobre la cuestión destacaba Leandro N. Alem, figura procedente del alsinismo porteño y más tarde fundador de la Unión Cívica Radical (UCR), para quien la federalización de Buenos Aires era obra de una "violenta vocación centralista que se hace contra el sistema federal" (Alem, 1912: 138). A su entender, esto no podía sino abrir un porvenir sombrío para el régimen federal, toda vez que aquella ciudad, a la que consideraba el único centro dotado de "fuerza moral" capaz de poner límite al "Poder Central", quedaba desde entonces sometido al imperio de este último. ${ }^{6}$ En el ascenso, durante la década de 1880, de ese al que también llamaba "Poder General", vio otro signo de la corrupción moral que denunciaba y que lo llevó participar activamente en las revoluciones de 1890 y de 1893 (Gallo, 2009: 60). Convencido defensor de la preexistencia de las provincias, que lo conducía a sostener que la nación sólo era resultado de un pacto de unión entre aquellas, Alem no veía en el orden político configurado bajo el predominio del Partido Autonomista Nacional (PAN) una forma posible de federalismo, sino su decidida y obscena desnaturalización.

La idea de que el federalismo argentino poseía una naturaleza específica que podía ser revelada mediante el estudio de su historia, como también la convicción de que la evolución política de la década de 1880 no iba sino en contra de

6 Pese a su estatus de distrito federal, se otorgó a la ciudad de Buenos Aires plena representación en las dos cámaras del Congreso. Para Estrada, la representación de la Capital Federal en el Senado era una anomalía, que sólo se explicaba como resultado de "una concesión a las exigencias localistas de los habitantes del territorio federalizado de la capital" (1895: 446). 
esa naturaleza, llevó a Francisco Ramos Mejía a publicar, en 1887, El federalismo argentino. En base a un enfoque centrado en la historia argentina, en el que las escasas alusiones a los Estados Unidos evidenciaban un claro descrédito hacia el ejercicio de tomar su experiencia como modelo de federalismo, Ramos Mejía argumentaba en favor de la preexistencia de las provincias. Pese a coincidir con Estrada en el énfasis con el que ambos señalaban la necesidad de dejar de lado la experiencia de otros federalismos para concentrarse así en el estudio de la "constitución orgánica del pueblo argentino" (Ramos Mejía, 1889: 334), las conclusiones que cada cual obtenía no podían ser más diferentes. Mientras que para Estrada la República Argentina "no es una Nación compuesta de Estados; [sino] un Estado dividido en provincias" (1895: 293), para Ramos Mejía "no es una unidad descentralizada como se ha pretendido, sino una unión de entidades, antes independientes" (1889: 285).

Pero esta cuestión era secundaria respecto de la que constituía el interés más importante de Ramos Mejía, a saber, demostrar que el federalismo argentino no había respondido a la adopción de una forma de gobierno entre otras, sino que era el resultado necesario de "una evolución orgánica que vino operándose lentamente desde los orígenes remotos del país argentino y hecha visible en su momento oportuno" (1889: 307). Las raíces de ese desarrollo multisecular eran remontadas a los tiempos de las tribus ibéricas anteriores al Imperio romano, desde cuando se había ido desarrollando un "particularismo peninsular" que, más tarde combinado con el "espíritu democrático" surgido de las particulares condiciones de la vida colonial en América, terminaría por dar lugar al federalismo argentino como "la manifestación del rasgo etnográfico más culminante de toda una raza” (Ramos Mejía, 1889: 354). Pero si este acento en el carácter orgánico de las provincias permitía mostrar a los gobiernos que promovían la concentración de funciones en el Estado nacional como contrarios a la constitución natural del pueblo argentino, a la vez sembraba dificultades para pensar la futura incorporación de los Territorios al sistema federal. La obra de Ramos Mejía no incluía ninguna mención a los mismos -el análisis se cerraba hacia 1820-, pero al concebir a las provincias como organismos de una larga maduración, el mero criterio demográfico que acababa de ser adoptado en la ley de Territorios quedaba seriamente cuestionado.

La preferencia por un enfoque histórico como clave interpretativa del federalismo argentino también aparecía en las reflexiones que en forma paralela Lucio V. López realizaba desde la cátedra de Derecho Constitucional, en la que sucedió a Estrada y en la que permaneció hasta su muerte, provocada por un duelo, en 1894. Su convicción en la utilidad de la historia como principal herramienta para comprender las formas jurídicas y los problemas institucionales del país, era indisociable de su queja contra la influencia, que juzgaba exagerada y nociva, de los juristas extranjeros -en particular franceses- sobre el derecho argentino. De allí que por ejemplo entendiera, coincidiendo con Ramos Mejía pero sin ir tan lejos en el pasado como éste, que "el estudio del foro colonial tiene un carácter especialísimo en la historia de los países americanos” (López, 1902:39). Desde esa perspectiva, los rasgos particulares que había asumido la organización política 
del país solo podían comprenderse indagando en el pasado, lo que venía a ser una comprobación de la observación más general de que "la división territorial de los Estados depende directamente de su historia” (López, 1902: 78).

En el caso argentino, esa historia había determinado que el Estado estuviera integrado por provincias y por Territorios, además de otras fracciones de menor magnitud. Mientras que las primeras constituían "personas jurídicas" dotadas de "carácter político", los segundos sólo constituían divisiones administrativas colocadas bajo "gobiernos de excepción y temporarios en nuestro orden federativo", que sin embargo "por el desarrollo de su población y de su riqueza están llamados a ser provincias argentinas” (López, 1902: 179). El Congreso era, según las disposiciones constitucionales, el encargado de elevarlos a la condición de provincias e incorporarlos así a la forma federal de la república. "Entretanto y mientras se prepara paulatinamente este gran acontecimiento", señalaba López, "son dependencias de la Nación, no son entidades independientes, carecen de constitución propia y por consiguiente de poderes políticos como los Estados" (1902: 179). Con todo, es menester advertir que si bien López entendía que los Territorios no podían tener otro destino que el de dar lugar a nuevas provincias, su detallada descripción de la organización institucional de dichos espacios omitía por completo el único requisito que la ley de 1884 establecía para tal transformación. En cambio, aquello que la misma ley disponía para la instalación de las legislaturas territoriales, esto es, la existencia de una población de más de treinta mil habitantes, era juzgado por López conveniente para propiciar "el adelanto futuro de los territorios" (1902: 179).

Esta aparente disparidad de criterio frente a dos usos de una fórmula puramente demográfica no escondía ningún juicio negativo sobre la capacidad política de los pobladores de los Territorios. López llegaba de hecho a señalar la necesidad de otorgarles representación en la Cámara de Diputados, mediante delegados que, con voz pero sin voto, pudieran transmitir a los legisladores las necesidades de sus distritos. El problema estribaba en una dimensión más compleja. La regla demográfica le era aceptable para permitir la formación de instituciones que favorecieran la adquisición de personalidad política por parte de los Territorios, como las legislaturas y los municipios. Sin embargo, no parecía pensar lo mismo respecto de la posibilidad de sujetar la conversión de un Territorio en provincia a un mero volumen demográfico. En efecto, la calidad provincial no era concebida por López como algo que pudiera derivarse de un único factor, como lo hacía la ley 1.532 con la cantidad de población, o como lo había hecho Estrada con la capacidad financiera. Para López, las provincias constituían un resultado del trabajo de la historia y de ningún modo eran entidades que podían ser sencillamente creadas por las autoridades federales apelando a alguna fórmula puntual. Aun cuando defendía la tesis de la preexistencia de la nación, acercándose a Alberdi y a Estrada, se distanciaba de éstos, aproximándose a Ramos Mejía, al sostener que la Argentina era una "federación orgánica" que había alcanzado forma política tras pugnar por décadas contra el legado "centralista y absorbente” del Imperio español (López, 1891: 75). De todo esto se desprendía, 
a contramano de lo dictado en la ley, que los Territorios sólo podrían alcanzar calidad provincial como resultado de su maduración como organismos colectivos, algo que ninguno de esos espacios de menos de una década de existencia institucional parecía próximo a ser.

Tras la muerte de López, su cátedra pasó a estar a cargo de Aristóbulo del Valle, aunque por un breve periodo hasta su fallecimiento en 1896, pocos meses antes del suicidio de Alem en el invierno de ese mismo año. Pese a haber acompañado a este último en las revoluciones de 1890 y de 1893, contándose también entre los fundadores de la UCR, la mirada que Del Valle tenía acerca del federalismo argentino presentaba notorias diferencias con la del líder radical. Para Del Valle, las provincias no eran sino "fracciones de una nación" (1895:11), a la que concebía como preexistente a aquellas. En línea con los planteos de Alberdi y de Estrada, el régimen federal era en sus clases presentado como una forma de gobierno que la nación argentina se había dado a sí misma, pero de ningún modo como aquello que había hecho posible su existencia. De allí el rechazo de Del Valle hacia las interpretaciones de quienes identificaban los orígenes de las provincias, y por extensión del federalismo, con instituciones del periodo colonial como los cabildos. En este sentido, las provincias no constituían en su mirada entidades naturales con existencia propia, sino demarcaciones administrativas dispuestas por la nación, que por consiguiente podía también deshacerlas o modificarlas. "Si una provincia desaparece", como Del Valle señalaba había ocurrido en el caso de Misiones, espacio federalizado en 1881, "el sujeto de derecho para adquirir el territorio es la Nación” (1896: 10). ${ }^{7}$ En el sentido contrario, los Territorios podrían ser declarados provincias con sólo alcanzar la cantidad de población a tal efecto prevista en la ley de 1884, aunque dicha posibilidad se mostraba todavía lejana según los resultados del censo nacional de $1895^{8}$

La que Del Valle ofrecía sobre el federalismo argentino no parecía ser una mirada aislada. En efecto, las reflexiones que por esos años realizaba sobre la misma materia Luis V. Varela, miembro de la Corte Suprema de Justicia durante toda la década de 1890, declaraban su pertenencia "a la escuela que reconoce la preexistencia y la preeminencia de la autoridad nacional sobre los gobiernos de las provincias" (1896: VI). Según Varela, nacido en el exilio montevideano de su padre Florencio, "en ningún documento, en ninguna manifestación de pueblos o de gobiernos, aparece el individualismo de las provincias [...] como entidades políticas que se desprendían de una parte de su propia autonomía para constituir esta entidad moral que hoy figura entre las grandes naciones, con el nombre de República Argentina" (1896:VII). Las provincias habían adquirido existencia institucional y personalidad política por el reconocimiento que de ellas había hecho la Constitución nacional, lo que implicaba que aquellas tenían "unas soberanías

7 Acerca de las pretensiones de la provincia de Corrientes sobre la región de las antiguas misiones, y también sobre las dificultades que tuvo para concretarlas, Buchbinder (2004).

8 Según dicho censo, los nueve Territorios Nacionales sumaban en conjunto apenas poco más de cien mil individuos, una pequeña fracción de los casi cuatro millones registrados para todo el país. Entre los Territorios, el que contaba con la población más numerosa era Misiones, con 33.163 habitantes. República Argentina, Segundo censo nacional. Mayo 10 de 1895. Tomo II. Buenos Aires: Taller Tipográfico de la Penitenciaría Nacional, 1898, p. XXI. 
relativas, dentro de la soberanía absoluta, constituida por la Nación” (Varela, 1896: VIII-IX). Esta última ejercía autoridad exclusiva sobre los Territorios, cuyo régimen de gobierno padecía según Varela "una deficiencia notable en lo referente a la política", dado que en dichos espacios existían "millares de argentinos que están privados del derecho de sufragio en todas las cuestiones nacionales" (1896: XII). La entidad provincia estaba así lejos de ser vista por Varela como la unidad principal de organización del sistema representativo, cuya extensión más allá de las unidades de dicha condición le resultaba aceptable.

La búsqueda de una armonización entre las posiciones que otorgaban preexistencia a la nación y aquellas que la atribuían a las provincias tuvo una expresión más clara en la pluma de Joaquín V. González. En su Manual de la Constitución Argentina, preparado para ser empleado en la instrucción media, González afirmaba la simultaneidad de origen de ambas entidades señalando que "las Provincias, ya aisladamente, ya formando parte de ligas [...] nunca se realizaron en desconocimiento de su dependencia de una misma Nación, que todos deseaban ver constituida, es decir, organizada en el territorio que comprendían" (González, 1897: 81). Esto lo llevaba a presentar al argentino como un "federalismo mixto", en el que el Estado federal y las provincias tenían cada uno sus bien delimitadas órbitas de acción por instituciones políticas adoptadas de otros países pero que eran al mismo tiempo "resultado de una larga evolución histórica” (González, 1897: 701). Una concepción que, en parte tributaria del principio liberal de división del poder, buscaba situarse por encima de la denuncia de una corrupción centralista del federalismo como también de la de provincianismo estrecho, pero que sobre todo se ajustaba bien a su condición personal de político del interior y de figura relevante dentro del autonomismo nacional (Roldán, 1993). Desde este punto de vista, el riojano no consideraba los subsidios del Estado federal como un instrumento de sometimiento de las autonomías provinciales -como coincidían en señalarlo Estrada, Alem y López, entre otros-, sino como "un deber de protección" hacia las provincias, que al formar la unión nacional, se habían despojado de muchos de sus recursos fiscales (González, 1897: 750).

Como es evidente, la capacidad financiera no era en absoluto concebida por González como el elemento decisivo de la personalidad provincial. Pero tampoco la sola cantidad de población. Una provincia constituía una entidad dotada de la "soberanía inherente" que la facultaba a darse su propia constitución, "el código que condensa, ordena y da fuerza imperativa a todo el derecho natural que la comunidad social posee para gobernarse” (González, 1897: 707). Los Territorios, en cambio, se definían por su carencia de derechos políticos, "que son parte del gobierno mismo y de los que pueden ser privados hasta que obtengan plena capacidad” (González, 1897: 483). Así, si bien señalaba que la ley vigente decía que podían ser transformados en provincia si contaban con más de sesenta mil habitantes -lo que de todos modos no amenazaba con producirse en lo inmediato, según los datos del censo de 1895 ya señalados-,González entendía que ese cambio de estatus no podía fundarse en ese único elemento. Antes que en una simple constatación demográfica, los Territorios debían ser convertidos en provincias 
"cuando llenen las condiciones de capacidad, de la ley, para un gobierno propio y para gozar de las prerrogativas de Estados confederados, al igual que las antiguas Provincias" (González, 1897:479). En consecuencia, el Congreso no podía inventar provincias, sino sólo reconocerlas allí donde ya se hubiesen formado mediante el desenvolvimiento de sus propias fuerzas sociales.

\section{Bajo la lupa de la ciencia}

En la década de 1890, los discursos que denunciaban una degradación centralista del federalismo, no perdieron vigor en la escena pública. Por el contrario, durante esos años de intensa agitación política, constituyeron una parte muy importante del repertorio argumental de quienes impugnaban el orden político construido por el PAN. Para radicales como Alem, aún más preocupado por la limitación del poder que en la década anterior, el federalismo representaba uno de los pilares fundamentales de la república que pretendían restaurar, ya por vía revolucionaria, ya por vía electoral. En la mirada del líder radical, los años noventa mostraban la profundización del rumbo centralista emprendido en el decenio previo, trazando un círculo vicioso en el que la endémica precariedad de las provincias las sometía a un Poder Ejecutivo que convertía a los gobiernos de aquellas en instrumentos con los cuales dominaba el Congreso (Gallo, 2009: 63). Frente a ese sombrío escenario, otros desencantados con la evolución política del país, como Manuel D. Pizarro (1898), ex gobernador de Córdoba y anterior ministro de Roca, optaban por declarar definitivamente muerto al régimen federal y sugerir que la adopción de un sistema unitario ofrecía la única salida a la tensión que la nación vivía entre sus formas jurídicas y las de una sociedad en franca modernización.

Esa percepción de la sociedad argentina como sujeta a vertiginosas transformaciones que no derivaban de la acción gubernamental sino de fenómenos de escala inclusive transnacional, abrió hacia el fin de siglo una clara disposición hacia enfoques que prometían hacer más inteligibles tales cambios (Terán, 2008). En el ámbito del derecho, se hizo notorio el entusiasmo con el cual el modelo de una observación científica de la sociedad y las instituciones fue adoptado por quienes hallaban en él un instrumento de análisis más incisivo que el de una disciplina jurídica hasta entonces orientada a la doctrina y a la historia. En lo que aquí interesa, las insuficiencias advertidas en las instituciones representativas y burocráticas como consecuencia de esos cambios, lanzaron a diversas figuras provenientes del derecho en busca de un saber científico sobre los campos de la política y de la administración, a partir del cual fuese posible ofrecer a esos problemas otras respuestas que el solo deseo de restauración de una presunta armonía originaria.

Estos cambios pueden ser reconocidos al advertir, por ejemplo, las diferencias entre los cursos de derecho dictados por López y aquellos que al inicio del siglo XX ofrecía Adolfo F. Orma. Mientras que los del primero comenzaban con una extensa reseña histórica de las instituciones argentinas, los del segundo se abrían 
con una serie de definiciones de pretendida validez universal como aquella que se ofrecía al presentar a la "ciencia administrativa" como "la exposición de principios y reglas científicas permanentes e inmutables, aplicables indistintamente a todos los Estados" (Quirós y Emiliani, 1902: 25). Desde esta perspectiva, se asumía que el derecho debía servirse de los saberes de las ciencias no jurídicas, como se hacía al advertir que "necesitará de la sociología para el estudio y resolución de las cuestiones sociales; y máxime en la actualidad, que graves problemas de ciencia social se debaten con pasión por todos los pueblos” (Quirós y Emiliani, 1902:34). Este cambio de foco implicaba, por un lado, un alejamiento aún más pronunciado de la experiencia estadounidense como fuente de referencia, al mismo tiempo que, por el otro, una significativa inclinación hacia autores europeos, en particular procedentes del ámbito español y alemán. Aunque en el curso de Orma las definiciones relativas a la organización territorial no mostraban ninguna originalidad respecto de las que sobre la misma cuestión había ofrecido López -al punto de que sólo se reproducían las observaciones de este último acerca de la insuficiencia de la superficie, la población o la riqueza como criterios de organización del territorio-, aquella inspiración sociológica adquiría mayor peso cuando se trataba de pensar el estatus de dichas unidades.

Las provincias, por una parte, consideradas producto de "poderosos antecedentes históricos" -que a su vez explicaban que algunas "carezcan de capacidad económica para ser verdaderas provincias” (Quirós y Emiliani, 1902: 60)-, eran pese a todo descriptas como "personas jurídicas", lo que hacía de ellas, además de secciones del gobierno general, unidades políticas con la facultad de darse su propio gobierno y de tomar parte en el sistema representativo. Los Territorios, por otro lado, eran retratados como simples divisiones administrativas y, acerca de su eventual transformación en provincias, ni siquiera se mencionaba lo establecido en la ley. ${ }^{9}$ Desde la perspectiva de inspiración sociológica que se buscaba desplegar, se planteaba la necesidad de distinguir entre la noción puramente estadística de población, el simple "conjunto de habitantes contenidos en un determinado espacio de territorio", y aquella otra de pueblo, que en cambio "entraña personalidad, ciertos caracteres sociológicos, que nacen de la comunidad de origen, de tradiciones, de aspiraciones, etc.” (Quirós y Emiliani, 1902: 78-79). De tal razonamiento se desprendía, en primer término, que pese a sus precariedades financieras las provincias constituían personas jurídico-políticas ya constituidas y, en segundo lugar, que la adquisición de esa personalidad por parte de los Territorios no podía resultar de un determinado volumen demográfico, sino de aquello que, al parafrasear al jurista alemán Max von Rümelin, se imaginaba como fruto de una "biología de la sociedad” (Quirós y Emiliani, 1902: 79). En otros términos, una provincia constituía desde tal perspectiva una entidad social orgánica no resultante de -ni reductible a- una simple demografía. Apenas dos décadas de existencia institucional parecían insuficientes para que los Territorios consumaran esa evolución.

9 Es posible considerar que esa concepción de los Territorios se haya visto reforzada con la creación, en 1900, del Territorio Nacional de Los Andes, en la Puna de Atacama, como producto de la resolución de las disputas limítrofes mantenidas con Chile (Zusman y Hevilla, 2014). En 1943, la gobernación de Los Andes resultó disuelta en favor de las provincias vecinas de Jujuy, Salta y Catamarca. 
Otra mirada de vocación científica fue la que pocos años más tarde Rodolfo Rivarola propuso sobre las instituciones políticas del país, lo que necesariamente lo llevó a tocar la problemática del régimen federal. En 1908 publicó Del régimen federativo al unitario, una de las obras que le reportó mayor notoriedad, y que se abría con la provocadora aspiración de poner en discusión al que tachaba de "dogma federalista", bajo la convicción de que "dogma que se discute perece, y el federalismo argentino perecerá” (Rivarola, 1908:VII). Ese desenlace se le revelaba como un hecho sociológico de muy sencilla comprobación. La capitalización de Buenos Aires, la efectiva unificación del espacio nacional a través del ferrocarril y el telégrafo, y la expansión de un sistema escolar sostenido por el Estado federal, le demostraban que la evolución hacia un régimen unitario resultaba inevitable (Roldán, 2015: 232). Tal cambio de sistema le parecía además deseable porque concebía al federalismo como un régimen al que la propia evolución de la sociedad argentina había vuelto obsoleto y que debía ser superado para posibilitar progresos aún mayores que los alcanzados. Ya en Partidos políticos. Unitario y federal, publicado en 1904, Rivarola se había referido al federalismo como un molde institucional que la fuerza de las circunstancias había obligado a adoptar en 1853 -siguiendo en esto los planteos de Alberdi y de Estrada-, pero que desde 1880 permanecía como un elemento que entorpecía una acción gubernamental que, en lugar de atender las necesidades del pueblo de la nación, quedaba atrapada en permanentes negociaciones con los gobernadores de provincia y sus maquinarias políticas. ${ }^{10}$ Por si esto fuera poco, el régimen federal era señalado por Rivarola como causa del falseamiento de la representación que afectaba a la república, toda vez que las provincias tenían en la política nacional un peso que excedía al que tenían en la vida social y económica del país. Así, juzgaba inadmisible que provincias "inferiores en población, riqueza, industrias, etc., tal vez a cualquiera parroquia de la Capital [Federal]" (Rivarola, 1908: 379), como La Rioja, Catamarca, San Juan, San Luis y Jujuy, controlasen sin embargo la tercera parte del Senado. Titulares de una autonomía que su crónica pobreza hacía testimonial, y siendo así una carga que cada año consumía significativas porciones del presupuesto nacional, la soberanía de las provincias no se revelaba más que como "una palabra hueca ante la soberanía de la nación” (Rivarola, 1908: 366). El federalismo no era sólo para Rivarola arcaico sino además irrealizable, por lo que en lugar de "empeñarse en cumplir una Constitución imposible" era más razonable "adoptar un régimen posible" (1908: 378), de carácter unitario y con un régimen municipal vigoroso como el que las provincias impedían.

Desde ese diagnóstico, la posición que Rivarola tenía en relación con los Territorios no podía ser más discordante con la que por esos años expresaban otros autores, como Agustín de Vedia, quien siguiendo la definición canónica sobre la cuestión, afirmaba que dichos espacios "son Provincias en vías de formación" (De Vedia, 1907: 286). Para Rivarola, en cambio, los Territorios aparecían como un prometedor ensayo del régimen unitario que auspiciaba. Mientras que describía a las

10 Una abundante historiografía, para cuyo detalle no se dispone de suficiente espacio, se ha ocupado de las dinámicas de las redes políticas existentes entre las dirigencias provinciales y las nacionales de las dos últimas décadas del siglo XX. Al respecto, además del clásico de Botana (1977), cabe destacar el más reciente cuadro ofrecido por Alonso (2010). 
provincias como "agrupaciones incipientes" atrapadas en recurrentes desórdenes provocados por sus rencillas locales, los Territorios le parecían, por su misma falta de autonomía, más tranquilos escenarios donde la población podía consagrarse al progreso necesario en esas tierras. Lejos de propiciar su transformación en nuevas provincias, Rivarola apuntaba en la dirección exactamente opuesta. No sólo porque entendía que "aumentar el número de Provincias es aumentar la ocasión para las alteraciones del orden público y el número de las intervenciones" (Rivarola, 1908: 390). También porque, además de la reforma del Senado nacional -para introducir la representación de los intereses "materiales y morales" de la sociedad (Roldán, 2006: 79) - y de la federalización de la entera provincia de Buenos Aires, Rivarola proponía "convertir en Territorios Nacionales o anexar a otras Provincias, algunas que por su escasez de población y de recursos, no deben pesar injustamente en la influencia en el Senado" (1908: 379).

Apreciaciones similares eran las que por esos años realizaba Manuel Montes de Oca, quien sucedió a Del Valle en la cátedra de Derecho Constitucional de la Universidad de Buenos Aires. Según Montes de Oca, para quien "la unidad nacional, como entidad moral, existía ya mucho antes de sancionarse la constitución de 1853" (1910a: 26), el federalismo argentino no derivaba de la simple adopción de un cierto modelo de gobierno por parte de los constituyentes. Aun cuando su análisis no ofrecía un tratamiento histórico como los acostumbrados por otros autores, entendía que "el sistema federativo adoptado por la República fue impuesto por las circunstancias", y que éstas habían llevado a "aceptar como Estados de la Nación a las diversas provincias que habían conservado su individualidad desde la desorganización de 1820" (Montes de Oca, 1910b: 236). Era ese accidental origen el que explicaba, según Montes de Oca, la existencia de provincias incapaces de afrontar los gastos de su propia administración y que debían ser a diario socorridas por el tesoro nacional. En base a esa realidad postulaba, en la línea de Estrada y de Rivarola, que "si un Estado carece de capacidad financiera para gobernarse a sí mismo, no puede ni debe, en términos generales, formar parte como entidad autonómica de un país federativo", sino que "debe ser equiparado a los territorios nacionales y caer bajo la jurisdicción directa del gobierno central" (Montes de Oca, 1910b: 236). No obstante lo conveniente que un principio tal podía tener desde el punto de vista de la ciencia política, concebida como una "ciencia práctica" de reforma de los sistemas de gobierno (Montes de Oca, 1910a: 75), Montes de Oca no llegaba a proponer la sustitución del régimen federal por uno de tipo unitario. Para los Territorios, esto significaba admitir que darían lugar a nuevas provincias, en base al criterio demográfico de la ley 1.532 que Montes de Oca se limitaba a mencionar.

El reconocimiento de la precariedad financiera de muchas provincias no siempre se traducía en el rechazo del federalismo. José Nicolás Matienzo, quien tuvo al propio Estrada como profesor durante sus estudios universitarios, admitía como una realidad insoslayable que muchas provincias argentinas, "casi siempre afligidas por el déficit de sus presupuestos, se hallan de ordinario en posesión de un sobrante inútil de soberanía" (Matienzo, 1910:334). En esa debilidad encontraba Matienzo una de las razones que explicaban que, en una línea similar con la 
mirada de Rivarola, "desde 1880, se acentúa cada vez más la tendencia de los gobernadores a convertirse en agentes políticos del presidente” (1910:211). A ese rumbo de concentración del poder no sólo lo juzgaba pernicioso porque desvirtuaba el régimen federal, sino también porque esa colusión entre gobernadores y presidente producía el falseamiento de la representación democrática. ${ }^{11}$ Pero no obstante el oscuro perfil que observaba en el federalismo argentino, Matienzo rechazaba la solución de quienes como Rivarola propagaban la adopción de un régimen unitario. En cambio, entendía que el camino para volver auténtica la representación democrática que daba verdadero cuerpo al régimen federal radicaba en reducir el poder de las provincias, quitándoles las facultades que la reforma constitucional de 1860 les había otorgado en respuesta a las exigencias entonces planteadas por los representantes de la provincia de Buenos Aires para concretar su incorporación a la Confederación (Matienzo, 1910:338). Descubierta así la que para Matienzo era la realidad de las autonomías provinciales, la conveniencia de su inminente otorgamiento a los Territorios quedaba muy relativizada, precisamente cuando algunos de ellos habían alcanzado el umbral demográfico exigido por la ley de 1884, llevando a algunos diputados nacionales a la formulación de los primeros proyectos de ley de reconocimiento de esas gobernaciones como nuevas provincias. ${ }^{12}$

Sin llegar tampoco a la propuesta extrema de Rivarola, que tuvo una previsible fría recepción entre las dirigencias políticas de la época, otros estudiosos del derecho retomaron algunos de los planteos formulados por él. Uno de ellos fue Ángel F. Ávalos, jurisconsulto correntino radicado en Córdoba, quien más allá de una intermitente participación en la vida política de dicha provincia, destacó por su labor educativa en la misma y por una trayectoria como publicista que lo llevó a ocuparse de una apreciable variedad de temas. Aun cuando no suscribió el abierto rechazo que del federalismo hacía Rivarola, al que consideraba un "eminente maestro, gloria de las ciencias y letras nacionales” (Ávalos, 1920: 29-30), no dejó de servirse de los planteos de aquel para pensar la realidad del régimen federal. En particular, el camino que Ávalos se propuso explorar consistía en adoptar la perspectiva científica que identificaba en Rivarola pero para ponerla al servicio de una profunda reforma -y no de la supresión- del federalismo argentino. Era en razón de esta ambiciosa aspiración que contemplaba a los diez Territorios ya no como otras tantas nuevas provincias, sino como la materia de la que debía surgir un número mucho mayor de ellas, permitiendo así equilibrar el régimen federal mediante la multiplicación de sus actores.

11 Su argumento de que la Constitución vigente "no garante al pueblo contra los gobiernos, sino a los gobiernos contra el pueblo" (Matienzo, 1910: 341), sería ampliamente utilizado por el radicalismo yrigoyenista para justificar su política de intervenciones federales. Cabe recordar que el propio Matienzo ocupó el cargo de Procurador General de la Nación durante casi toda la presidencia de Hipólito Yrigoyen. Buenos Aires y de San Luis respectivamente, elaboraron un proyecto de ley proponiendo la realización de un censo de población para el caso del Territorio de La Pampa y, en caso de comprobarse la existencia de al menos sesenta mil habitantes, declararlo provincia en el Centenario de la Revolución de Mayo. Ni ese proyecto, ni el que con el mismo propósito los dos legisladores presentaron en 1910, fueron debatidos por la Cámara. Diario de Sesiones de la Cámara de Diputados de la Nación, sesión del 24/8/1910. 
Pero la transformación de los Territorios en nuevas provincias, no podía según Ávalos resultar de un acto de mera voluntad política, aunque estuviese motivada por aquellos sanos propósitos. Defensor de la preexistencia de la nación y convencido de que las provincias eran gran parte producto del tumultuoso periodo abierto en 1820, Ávalos entendía que aquellas que hubiesen de nacer en el futuro "deben surgir como un efecto bien determinado de las leyes políticas y un fruto maduro de las fuerzas sociales, y no como un organismo de vida precaria, o por obra de la violencia, como algunas de nuestras antiguas Provincias, surgidas entre la vorágine de las convulsiones civiles” (1915: 10). Esto no sólo significaba poner en cuestión el criterio demográfico que a tal efecto establecía la ley de Territorios, sino también contestar en forma directa los reclamos de los grupos que, como los aparecidos en La Pampa bajo el liderazgo del terrateniente y varias veces diputado nacional Pedro O. Luro, demandaban la inmediata provincialización señalando que el umbral de los sesenta mil habitantes había sido satisfecho con amplitud, pero además que la gobernación superaba, tanto en población como en riqueza, a varias de las provincias existentes. ${ }^{13}$ Esto que era planteado por tales grupos como una injusticia, no lo era forzosamente para Ávalos quien, condensando las elaboraciones que diferentes juristas habían realizado a lo largo de más de tres décadas, afirmaba que "hay que tener en cuenta factores morales, a más de la población y de la riqueza, y ver si justamente con la condición del número de habitantes exigido para la mera posibilidad de la autonomía, se han cumplido otras condiciones esenciales fijadas por la ley de Territorios" (1915: 7). En particular, Ávalos sostenía que no podían formarse provincias allí donde faltaba "la verdadera célula del federalismo para los Territorios", que no era otro que "el funcionamiento regular, constante y definitivo de la Legislatura Territorial” (1915: 8), algo que no se había producido en ninguna de las gobernaciones. Aunque la normativa no establecía de manera explícita que la existencia de una legislatura fuese imprescindible para el otorgamiento de calidad provincial, Ávalos defendía que el verdadero espíritu de los legisladores había sido hacer de dicha institución un instrumento de desarrollo de la personalidad política de los Territorios y que por lo tanto se trataba de una etapa que no podía ser sorteada, aun cuando no se hubiese producido su implementación.

La aspiración de Ávalos de promover un rediseño del régimen federal adquirió más difusión con la aparición, en 1920, de su Problemas del federalismo argentino, en el que reunía una serie de estudios publicados en los años previos. En su nuevo formato, la reaparición de esos escritos era un modo de insistir en que la futura admisión de los Territorios como provincias exigía evaluar "diversos órdenes de la cultura general" y además fraccionar esos espacios en unidades de menor extensión, de manera de anticiparse a las fuerzas económicas y sociales que a su entender darían también lugar a la división de la provincia de Buenos Aires en otras cuatro, y en por lo menos dos a las de Santa Fe, Corrientes, Córdoba, Entre Ríos, Mendoza y Salta (Ávalos, 1920: 4). Esta evolución del régimen federal era según Ávalos factible porque la unidad nacional estaba 
definitivamente consolidada, pero resultaba además conveniente porque las provincias tenían extensiones excesivas y porque eran en su mayor parte producto de la "descomposición" de 1820, antes que del recurso a "un ideal político y sociológico aplicable a la creación de nuevos estados provinciales” (1920: 6). Sin llegar al rechazo del federalismo, la invitación de Ávalos a reestructurarlo con el auxilio de la ciencia moderna, no encontró entre las dirigencias políticas de la época mejor eco que el de las propuestas de Rivarola. Sin embargo, parece posible entender que sus opiniones sobre los Territorios, nutridas de las que con anterioridad habían ofrecido autorizados juristas, pudieron haber hallado alguna sintonía entre la mayoría de los legisladores del Congreso, quienes desestimaron el proyecto de reconocimiento de La Pampa como nueva provincia formulado por el Poder Ejecutivo Nacional en 1919 y volvieron a hacerlo en 1921 ante una iniciativa del mismo origen que, además de aquella gobernación, comprendía también a la de Misiones.

\section{Conclusiones}

Este recorrido por las ideas formuladas por diversas figuras relevantes del pensamiento constitucional argentino entre 1870 y 1920, confirma la observación que José Carlos Chiaramonte y Pablo Buchbinder (1992) realizaran sobre la preeminencia que los enfoques de tipo histórico sobre la materia adquirieron en ese periodo. Como se pudo comprobar, la búsqueda, a partir de la década de 1870, de una perspectiva argentina que permitiera abordar los problemas constitucionales y federales sin adoptar una postura tributaria de tratadistas extranjeros, permite advertir "la conformación de una especie de diálogo entre historiadores y juristas que alimenta las obras de ambos campos" (Chiaramonte y Buchbinder, 1992: 111). Por otra parte, si bien ese diálogo tendió a seguir el rumbo de quienes sostenían la tesis de la preexistencia de la nación, dejando un terreno cada vez más estrecho para los que buscaban defender una concepción "contractualista" (Chiaramonte y Buchbinder, 1992: 120), también es cierto que esos debates condujeron a que el federalismo llegara a ser imaginado como un rasgo esencial de la nación argentina, haciendo todavía más angosto el espacio -intelectual, pero sobre todo político- para cualquier propuesta de reemplazo de dicho sistema por uno de tipo unitario.

Pero más allá de estas comprobaciones, este estudio permite descubrir un aspecto menos advertido en otros análisis, aunque de todos modos crucial para comprender el desenvolvimiento histórico del federalismo argentino, como es el que remite a la misma calidad provincial. Si bien existe una voluminosa historiografía dedicada a dar cuenta de los procesos que condujeron a la formación de las provincias, los estudios sobre el federalismo en la segunda mitad del siglo XIX tendieron por lo general a asumir dicha calidad como algo dado y a concentrarse, en cambio, en las transformaciones operadas en las relaciones entre el Estado nacional y las provincias. Enfoque sin duda legítimo, donde las provincias aparecen como piezas ya constituidas de un juego en el cual se 
dirime la distribución de poder, de representación política y de recursos, pero en el que la propia condición provincial permanece fuera de toda discusión. Por supuesto, catorce provincias ya existían, pero ¿fue siempre su entidad política concebida como un atributo definitivo? Como se espera haber comprobado en este estudio, no pocas y menos aún marginales figuras de la vida académica del último tercio del siglo XIX y comienzos del siglo XX entendían que la calidad provincial no era de ningún modo irreversible.

Esta cuestión, tan decisiva en los debates librados en torno al federalismo durante dicho periodo, y que no parece perceptible cuando la mirada se limita al conjunto de las provincias, resulta en cambio evidente al ampliar el foco hasta incluir también a esa otra mitad de la superficie argentina que conformaban los Territorios Nacionales. Desde su invención concebidos como escenarios de provincias futuras, su aparición obligó a pensar de forma explícita en qué consistía la calidad provincial y qué elementos la determinaban. Las respuestas que los autores aquí analizados dieron a tales preguntas fueron diversas y no siempre señalaron los mismos factores como generadores de la calidad provincial. Dentro de esa variedad de perspectivas, es sin embargo posible reconocer que algunas alcanzaron prevalencia sobre otras que, sin desaparecer por completo, tuvieron cada vez menos gravitación. En este sentido, prácticamente todos los autores identificaron a la autonomía como el elemento distintivo de la calidad provincial. La invención de los Territorios y su definición como unidades carentes de autonomía, contribuyó a hacer más visible a esta última como el factor decisivo que diferenciaba a esos espacios respecto de las provincias. Si la adopción del término autonomía para designar lo esencial de la condición provincial allanó el camino a una gravitación excluyente del Estado federal -según el atento análisis de Agüero (2014)-, parece también necesario advertir que esa transformación no puso término a las impugnaciones enfrentadas por las provincias. En efecto, como sugieren los debates aquí revisados, apenas concretada la incorporación de aquella noción a los lenguajes jurídico e historiográfico, surgieron voces para las cuales el concepto de autonomía definía un campo semántico al que varias provincias se mostraban incapaces de cubrir en toda su extensión. A esos observadores, el uso no ya del término soberanía sino también el de autonomía les devolvía un excedente conceptual frente a la realidad que encontraban en muchas provincias. Esto no hizo que dejaran de concebir a la autonomía como el atributo esencial de la calidad provincial. En cambio, los condujo a sostener que las provincias que fuesen incapaces de sostener su autonomía, debían perder su condición de tales. Que propuestas de tal calibre no fueran puestas en práctica y que eventualmente llegaran a ser consideradas especulaciones ajenas a la realidad, señala los límites que conoció un proceso de centralización que no estaba destinado a detenerse allí donde lo hizo y que por lo tanto sugiere que el federalismo argentino constituía una materia política acaso más resistente de lo que una imagen convencional invita a suponer.

Por otra parte, el uso cada vez más difundido del término autonomía abrió nuevos interrogantes, como los que giraban en torno a cuáles eran los elementos concretos que determinaban esa capacidad. También en este sentido, la invención de los Territorios dio a esa pregunta un carácter más acuciante, toda vez que fueron 
concebidos como espacios que debían dar lugar a nuevas provincias. La respuesta que los legisladores dieron en 1884, sujetando la conversión de los Territorios en provincias a una cierta cantidad de población, fue ya desde entonces rechazada por la mayoría de los juristas, lo que pone en evidencia que no siempre había correspondencia entre las opiniones de quienes dictaban las leyes y quienes las hacían objeto de estudio. Según estos últimos, la presencia de un determinado volumen demográfico -en espacios además inventados por el propio Estado federal- no constituía ninguna fuente de capacidad autonómica. Como se recordará, algunos de los autores aquí revisados, al observar la realidad de varias provincias y al advertir cuán pesadamente esta gravitaba en su relación con las autoridades nacionales, señalaron a la capacidad económica y financiera como el factor crítico de una verdadera autonomía. Más numerosos fueron, sin embargo, los que rechazaban esa reducción de la autonomía a la condición económica y sostenían, en cambio, el criterio de considerar irreversible la autonomía reconocida a las provincias. Estos autores, con frecuencia provenientes del interior del país, tuvieron éxito en defender el principio, como pudo verse sometido a abundantes y autorizadas impugnaciones, de considerar a las provincias como personas indestructibles. La cuestión en torno a la que trabajaron en sus intervenciones públicas consistió en mostrar que las provincias eran organismos colectivos, dotados de personalidad jurídico-política y hasta poseedores de caracteres culturales distintivos, dimensiones todas ellas presentadas como irreductibles a una cantidad de población, a un monto de recursos financieros o a cualquier otro elemento específico. Todavía más, si hacia el cambio de siglo la circulación de nociones que prometían un conocimiento científico de la política y de la sociedad alimentó ataques contra las provincias, aquellos autores adoptaron esas herramientas y las pusieron al servicio de la empresa de probar que éstas eran personas resultantes de una larga maduración orgánica y que su autonomía era por lo tanto imprescriptible. De esta manera, al apuntalar la noción de autonomía como un atributo irreversible de toda provincia, vale decir como inherente a esa persona política, los juristas que para ello debieron enfrentar los juicios contrarios de otros autorizados pares, lograron situar la calidad provincial fuera del alcance de cualquier definición discreta de la misma, alternativa que encerraba el riesgo de hacer de aquella una calidad reversible según el examen del estado concreto de sus presuntos factores determinantes. En términos más simples, al resultar la calidad provincial protegida en forma exitosa frente a las amenazas políticas y doctrinarias que surgieron en el periodo aquí analizado, la fórmula demográfica de la ley de Territorios de 1884 quedó desprovista de toda validez jurídica como fundamento para la formación de nuevas provincias.

Es importante señalar que el análisis aquí desplegado demuestra la imposibilidad de referirse a los juristas como un colectivo de opiniones homogéneas acerca de los Territorios. La comprobación de esa variedad conduce, sin embargo, a la cuestión de las repercusiones prácticas y los efectos concretos que esos juicios tuvieron sobre la situación de dichos espacios. Ante esto resulta conveniente advertir que la relación entre las elaboraciones de los juristas y las motivaciones de los legisladores no puede ser reducida ni a una pura fabricación de argumentos doctrinarios para los últimos, ni a una mera traducción legal de las meditaciones 
de los primeros. Sin negar tales posibilidades, parece de todos modos necesario entender que esas relaciones pueden presentar formas muy diversas. En lugar de intentar dar cuenta de todas sus expresiones posibles, el propósito específico de este estudio consistió en reconstruir los argumentos jurídicos disponibles a los usos, sinceros o fingidos, en definitiva múltiples, que los legisladores que se sucedieron en el periodo aquí considerado podían hacer de aquellos. Desde esta premisa, se espera haber demostrado que la problemática de los Territorios admite una lectura alternativa a la que podría sugerir, por ejemplo, que los juristas aquí analizados solo confeccionaban razonamientos para obstruir la admisión de nuevas provincias, en servicio de las existentes. En realidad, los usos de los argumentos jurídicos sólo pueden entenderse reconociendo primero su disponibilidad, lo que vuelve relevante estudiar los modos en que la cuestión de los Territorios fue tratada en el ámbito del derecho constitucional, sin que esto implique suponer que los usos que los actores políticos podían hacer de tales razonamientos puedan sencillamente derivarse del plano de la doctrina. Aquí se ha preferido mantener la distinción analítica entre ambos aspectos, dejando para otra oportunidad la exploración sobre cómo se articularon de forma concreta en las distintas coyunturas de la historia de los Territorios. En este sentido, el análisis desplegado aquí aspira a poner de manifiesto que la cuestión de los Territorios es relevante para el estudio de las instituciones representativas y federales -al menos desde el último tercio del siglo XIX-,y que tales espacios no deberían ser contemplados como una suerte de lado oscuro del federalismo argentino, donde ambiciones unitarias impracticables en el resto del país habrían podido desarrollarse sin impedimento alguno. Al ampliar la mirada más allá del conjunto de sus catorce provincias iniciales, para considerar también la mitad restante del territorio que llegó a ser nacional, resulta posible reconocer problemas medulares del federalismo que permanecen desatendidos cuando el foco se limita a dar cuenta de las relaciones entre aquellas y el Estado nacional. 


\section{Bibliografía}

" Agüero, A. (2014). “Autonomía por soberanía provincial. Historia de un desplazamiento conceptual en el federalismo argentino (1860-1930)", Quaderni Fiorentini, 43, pp. 341392.

" Agüero, A. (2017). “El 'constitucionalismo hispano', la eclosión municipal y la supresión de los cabildos en el Río de la Plata, primera mitad del siglo XIX", Dimensões, 39, pp. 52-82.

"Alberdi, J. B. (1852). Bases y puntos de partida para la organización política de la República Arjentina. Valparaíso: Imprenta del Mercurio.

" Alem, L. N. (1912). Escritos y discursos. Buenos Aires: Ferrari hnos.

" Alonso, P. y Bragoni, B. (eds.) (2015). El sistema federal argentino. Debates y coyunturas (1860-1910). Buenos Aires: Edhasa.

" Arias Bucciarelli, M. (ed.) (2013). Diez territorios nacionales y catorce provincias. Argentina, 1860/1950. Buenos Aires: Prometeo.

" Ávalos, Á. (1915). "Las gobernaciones nacionales y las futuras provincias argentinas. Tres nuevos capítulos de un estudio", Revista de la Universidad Nacional de Córdoba, II (2), pp. $1-32$.

" Ávalos, Á. (1920). Problemas del federalismo argentino. Córdoba: B. Cubas.

" Botana, N. (1977). El orden conservador. La política argentina entre 1880 y 1916. Buenos Aires, Sudamericana.

" Botana, N. (1993). “El federalismo liberal en Argentina: 1852-1930", en M. Carmagnani (ed.), Federalismos latinoamericanos: México / Brasil / Argentina. México: FCE, pp. 224259.

" Botana, N. (2015). “Epílogo”, en P. Alonso y B. Bragoni (eds.), El sistema federal argentino. Debates y coyunturas (1860-1910). Buenos Aires: Edhasa, 251-260.

" Botana, N. y Gallo, E. (1997). De la República posible a la República verdadera (18801910). Buenos Aires: Ariel, pp. 11-126.

" Bragoni, B. y Míguez, E. (eds.) (2010). Un nuevo orden político. Provincias y Estado nacional, 1852-1880. Buenos Aires: Biblos.

" Buchbinder, P. (2004). "Estado nacional y élites provinciales en el proceso de construcción del sistema federal argentino. El caso de Corrientes en la década de 1860 ", Boletín Americanista, 54, 9-34.

" Buchbinder, P. (2012). “Formación de sectores dirigentes y controversias políticas en el ámbito universitario: el caso de las facultades de derecho, 1890-1912", Boletín del Instituto de Historia Argentina y Americana Dr. Emilio Ravignani, 37, pp. 115-142.

" Cucchi, L. y Romero, A. L. (2017). “El 'modelo' norteamericano en la reglamentación de las intervenciones federales en la Argentina decimonónica. Debates en el Congreso Nacional (1869 y 1894)", Anuario de Estudios Americanos, 74 (2), pp. 615-642.

" Chiaramonte, J. C. (1993). "El federalismo argentino en la primera mitad del siglo XIX", en M. Carmagnani (ed.), Federalismos latinoamericanos: México, Brasil, Argentina. México: FCE, pp. 81-132.

" Chiaramonte, J. C. (1997). Ciudades, provincias, estados. Orígenes de la Nación Argentina (1800-1846). Buenos Aires: Ariel. 
" Chiaramonte, J. C. y Buchbinder, P. (1992). “Provincias, Caudillos, Nación y la historiografía constitucionalista argentina (1853-1930)", Anuario IEHS, 7, pp. 93-120.

"De la Fuente, A. (2007). Los hijos de Facundo. Caudillos y montoneras en la provincia de La Rioja durante el proceso de formación del Estado nacional argentino (1853-1870). Buenos Aires: Prometeo.

" De Vedia, A. (1907). Constitución argentina. Buenos Aires: Coni Hnos.

" Del Valle, A. (1895). Nociones de Derecho Constitucional. Notas tomadas de las conferencias del Dr. A. del Valle. II. Buenos Aires: La Buenos Aires.

"Del Valle, A. (1896). Apuntes de Derecho Constitucional tomados de las conferencias del Dr. A. del Valle sobre los artículos 13 hasta el 35 de la Constitución Nacional. Buenos Aires: Argos.

" Estrada, J. M. (1877). Curso de Derecho Constitucional. Conferencias del señor D. José Manuel Estrada en la Universidad de Buenos Aires. Buenos Aires: Imprenta del Porvenir.

"Estrada, J. M. (1885). Nociones de derecho federal. Notas in-extenso de las conferencias del catedrático D. José Manuel Estrada en la Universidad. Buenos Aires: Imprenta del Porvenir.

"Estrada, J. M. (1895). Curso de derecho constitucional, federal y administrativo. Conferencias dadas en la Universidad de Buenos Aires en los años 1877, 1878 y 1880. Buenos Aires: Compañía Sud-Americana.

" Gallo, E. (2009). Alem. Federalismo y radicalismo. Buenos Aires: Edhasa.

" Gallucci, L. (2016). “El espejismo de la República posible. La cuestión de la ciudadanía política y la organización institucional de los Territorios Nacionales (1884)”, Historia Crítica, 60, pp. 61-80.

" Gallucci, L. (2018). "Transmisiones y adaptaciones del federalismo. El tratamiento del régimen de los Territorios Nacionales en la enseñanza del derecho constitucional en la universidad argentina", Prismas. Revista de historia intelectual, 22, pp. 51-78.

" Goldman, N. (1998). “Los orígenes del federalismo rioplatense (1820-1831)", en N. Goldman (ed.), Revolución, República, Confederación (1806-1952). Buenos Aires: Sudamericana, pp. 103-124.

" Goldman, N. y Salvatore, R. (2005). Caudillismos rioplatenses. Nuevas miradas a un viejo problema. Buenos Aires: Eudeba.

" González, F. (1871). Lecciones de Derecho Constitucional. París: Librería de Rosa y Bouret.

" González, J. V. (1897). Manual de la Constitución Argentina. Escrita para servir de texto de instrucción cívica en los establecimientos de instrucción secundaria. Buenos Aires: Estrada y Cía.

" Halperin Donghi, T. (2015 [1972]). Revolución y guerra. Formación de una elite dirigente en la Argentina criolla. Buenos Aires: Siglo XXI.

" López, L. V. (1891). Curso de Derecho Constitucional. Extracto de las conferencias dadas en la Universidad de Buenos Aires por el Doctor Lucio V. López. Buenos Aires: Compañía Sud-Americana.

" López, L. V. (1902). Derecho administrativo argentino. Lecciones dadas en la Facultad de Derecho por el profesor de la materia Dr. Lucio V. López. Buenos Aires: Imprenta de La Nación.

" Matienzo, J. N. (1910). El gobierno representativo federal en la República Argentina. Buenos Aires: Coni Hnos. 
" Miller, Jonathan (1997). "The Authority of a Foreign Talisman: a Study of U.S.

Constitutional Practice as Authority in Nineteenth Century Argentina and the Argentine Elite's Leap of Faith", The American University Law Review, 46 (5), pp. 1483-1572.

" Montes de Oca, M. A. (1910a). Lecciones de Derecho Constitucional. Notas tomadas de las conferencias del doctor M.A. Montes de Oca. I. Buenos Aires: La Buenos Aires.

" Montes de Oca, M. A. (1910b). Lecciones de Derecho Constitucional. Notas tomadas de las conferencias del doctor M.A. Montes de Oca. II. Buenos Aires: La Buenos Aires.

" Myers, J. (1995). Orden y virtud. El discurso republicano en el régimen rosista. Buenos Aires: Universidad Nacional de Quilmes.

" Pizarro, M. D. (1898). "Vae victis. Carta sobre la muerte de la federación argentina”, Revista de Derecho, Historia y Letras, II (1), pp. 222-231.

"Quirós, H. J. y Emiliani, R. P. (1902). Derecho administrativo. Adaptado al programa vigente en la Facultad de Derecho y Ciencias Sociales de la Universidad de Buenos Aires, teniendo por base las conferencias del catedrático titular de la materia, Dr. Adolfo F. Orma. I. Buenos Aires: Valerio Abeledo.

" Ramos Mejía, F. (1889). El federalismo argentino. (Fragmentos de la historia de la evolución argentina). Buenos Aires: Lajouane.

" Rivarola, R. (1908). Del régimen federativo al unitario. Estudio sobre la organización política de la Argentina. Buenos Aires: Peuser.

" Roldán, D. (1993). Joaquín V. González, a propósito del pensamiento político liberal (18801920). Buenos Aires: CEAL.

" Roldán, D. (2006). “La República Verdadera impugnada”, en D. Roldán (ed.), Crear la democracia. La Revista Argentina de Ciencias Políticas y el debate en torno de la República Verdadera. Buenos Aires: FCE, pp. 53-102.

" Roldán, D. (2015). “El debate sobre el federalismo y las opacidades de la política argentina en el Centenario", en P. Alonso y B. Bragoni (eds.), El sistema federal argentino. Debates y coyunturas (1860-1910). Buenos Aires: Edhasa, pp. 223-249.

" Ruffini, M. (2007a). “Federalismo y ciudadanía política en la mirada de los juristas argentinos sobre los territorios nacionales”, Revista Nordeste, (26), pp. 3-22.

" Ruffini, M. (2007b). La pervivencia de la República posible en los territorios nacionales. Poder y ciudadanía en Río Negro. Bernal: Universidad Nacional de Quilmes.

"Sabato, H. (2008). Buenos Aires en armas. La revolución de 1880. Buenos Aires: Siglo XXI.

"Sabato, H. (2012). Historia de la Argentina, 1852-1890. Buenos Aires: Siglo XXI.

"Sabato, H. y Macías, F. (2013). "La Guardia Nacional: Estado, política y uso de la fuerza en la Argentina de la segunda mitad del siglo XIX", PolHis, 6 (11), pp. 70-81.

" Tanzi, H. J. (2011). “La enseñanza del Derecho Constitucional en la Facultad de Derecho de la Universidad de Buenos Aires", Academia. Revista sobre enseñanza del Derecho, 9 (17), pp. 85-112.

"Terán, O. (2008). Vida intelectual en el Buenos Aires fin-de-siglo (1880-1910). Derivas de la "cultura científica". Buenos Aires: FCE.

" Ternavasio, M. (2000). “La supresión del cabildo de Buenos Aires: ¿crónica de una muerte anunciada?", Boletín del Instituto de Historia Argentina y Americana Dr. Emilio Ravignani, 21, pp. 33-73.

"Ternavasio, M. (2002). La revolución del voto. Política y elecciones en Buenos Aires, 18101852. Buenos Aires: Siglo XXI. 
"Ternavasio, M. (2009). Historia de la Argentina, 1806-1852. Buenos Aires: Siglo XXI.

" Tocqueville, A. de (2010 [1835-1840]), La democracia en América. Madrid: Trotta.

"Varela, L. V. (1896). Estudios sobre la Constitución Nacional Argentina. I. Buenos Aires: Lajouane.

"Zimmermann, E. (2014). "Translations of the 'American Model' in Nineteenth Century Argentina: Constitutional Culture as a Global Legal Entanglement", en T. Duve (ed.), Entanglements in Legal History: Conceptual Approaches. Frankfurt am Main: Max Planck Institute, pp. 385-425.

"Zimmermann, E. (2015). "Soberanía nacional y soberanías provinciales ante la Corte Suprema de Justicia. Argentina, siglo XIX", Estudios sociales, XXV (48), pp. 11-37.

" Zusman, P. y Hevilla, M. C. (2015). “Panamericanismo y arbitraje en conflictos de límites: la participación de Estados Unidos en la definición de la frontera argentino-chilena en la Puna de Atacama (1899)", Cuadernos de Geografía. Revista colombiana de geografía, 23 (2), pp. 95-106. 